\title{
Cyclophyllidean cysticercoids from Echinogammarus tibaldii (Amphipoda, Gammaridae) from Lake Piediluco, Italy
}

\author{
Pavel N. Nikolov ${ }^{1}$, Boyko B. Georgiev1 ${ }^{*}$ and Bahram S. Dezfuli² \\ ${ }^{1}$ Central Laboratory of General Ecology, Bulgarian Academy of Sciences, 2 Gagarin Street, 1113 Sofia, Bulgaria; \\ ${ }^{2}$ Department of Biology and Evolution, University of Ferrara, St. Borsari 46, 44100 Ferrara, Italy
}

\begin{abstract}
In August 2007, 856 specimens of Echinogammarus tibaldii Pinkster et Stock, 1970 from the Lake Piediluco (Central Italy) were collected from 3 different sites and examined for larval helminths. Fourteen amphipods (1.63\%) were infected with larvae of Lateriporus teres (Dilepididae) and one amphipod (0.12\%) was infected with Microsomacanthus microsoma (Hymenolepididae). Adults of both species are known from waterfowl and gulls. The present results constitute new host records for both cestode species and the first finding of L. teres in Italy.
\end{abstract}

\section{Keywords}

Echinogammarus tibaldii, Lateriporus teres, Microsomacanthus microsoma, cysticercoids

Out of 5,100-5,200 known cestode species, the life cycles of fewer than 5\% have been described (Beveridge 2001, Georgiev 2003). Even in cases when the life cycle is known from experimental studies, the records from naturally infected intermediate hosts are important in gathering reliable information on host ranges of cestode species (Georgiev et al. 2006). In the course of a parasitological survey of Echinogammarus tibaldii Pinkster et Stock, 1970 (Crustacea, Amphipoda) from the Lake Piediluco (Central Italy), cysticercoids of two cyclophyllidean cestode species were found. The aim of the present article is to report the first record of cysticercoids in E. tibaldii.

Three samples of E. tibaldii from the Lake Piediluco (Central Italy, Terni Province) were obtained during August 2007. Overall, 856 specimens were collected using a dip net (mesh size $3 \mathrm{~mm}$ ) in shallow waters near overhanging vegetation. Amphipods were fixed in $8 \%$ formaldehyde. In laboratory, they were placed in Petri dishes and cleared in lactic acid before being measured, sexed and examined in toto. The number of larvae and the site of infection were recorded. The infected individuals were studied in glycerol, then dissected and the larvae were isolated and mounted in Berlese's medium. These whole mounts were used for morphological characterisation and identification of the cysticercoids. Two specimens were squashed in order to obtain more precise data on the rostellar hooks. In the following descriptions, the measurements are presented as the range with the mean and number of measurements taken (n) in parentheses; they are in micrometres unless otherwise stated.

The recorded cysticercoids were identified as Lateriporus teres (Krabbe, 1869) (Dilepididae) and Microsomacanthus microsoma (Creplin, 1829) (Hymenolepididae).

Lateriporus teres (Krabbe, 1869) (Figs 1-3 and 6)

Fourteen E. tibaldii $(9.0 \pm 0.3 \mathrm{~mm}$ long, mean length $\pm \mathrm{SE})$, 8 females and 6 males, were infected with $L$. teres (prevalence $1.63 \%$, intensity $1-4$, mean intensity 1.36 , mean abundance 0.022 ). The site of infection was documented in 5 host individuals. Four hosts were infected with single cysticercoids located in the 2nd-3rd, 3rd-4th and 5th-6th (2 hosts) thoracic segments. One host was infected with 3 cysticercoids located in the 4th-5th, 5th-6th and 6th-7th thoracic segments (Fig. 1).

The cysticercoids of L. teres (Figs 1-3, 6) had lemonshaped cysts, $1.1-1.7(1.3, \mathrm{n}=6) \mathrm{mm}$ long and 665-966 (850, $\mathrm{n}=6$ ) wide (Figs 1,2). The cyst wall consisted of four layers. The outer layer was undulate, with thickness $13(n=4)$, consisted of two sub-layers of equal width. The second layer was homogenous, with thickness from 5-9 $(7, \mathrm{n}=4)$ to $13-18(16$, 
$n=4)$. The third layer consisted of 2 sub-layers closely attached to one another: the outer one was transversely striated and 9-13 $(12, n=4)$ thick; the inner one presented a row of granules of various size, $5-13(9, \mathrm{n}=4)$ thick. The innermost layer was 22-45 $(31, \mathrm{n}=4)$ thick and consisted of fibrillar and granular elements. The scolex was withdrawn into the larval strobila, 550-720 $(623, \mathrm{n}=4)$ wide at the level of the suckers. The suckers were elliptical, muscular, 220-340 $\times$ 160-220 $(277 \times 193, \mathrm{n}=8)$. The rostellar sac was elliptical, $300-455 \times 168-210(391 \times 190, \mathrm{n}=4)$, passing beyond the posterior margins of suckers; its wall had a maximum thickness of $10(n=4)$. The retracted rostellum was 245-345 (291, $\mathrm{n}=4)$ long and 110-140 (126, $\mathrm{n}=4)$ wide; its wall had a maximum thickness of $10(n=4)$. The rostellar hooks (Figs 3, 6) were $13(n=2)$ or $14(n=3)$ in number; the total hook length was $150-168(156, n=7)$, with the blade $60(n=4)$ long and the hook base 95-100 (96, $\mathrm{n}=4)$ long; the blade length/total length ratio was $0.39(n=4)$. Cercomers were lacking.

One of the larvae of $L$. teres was developing, with formed rostellar hooks but not encysted. It was brownish, elongate, cylindrical, $1.4 \mathrm{~mm}$ long. Its body was 275 wide except the globular posterior part, which had a diameter of 505 .

Initially, cysticercoids of $L$. teres were found in Gammarus pulex (L.) in Germany and reported as "Cysticercus pa- chyacanthus (von Linstow, 1892)" in the early literature (Lühe 1910, Joyeux and Baer 1936). Spasskii (1954) showed that $C$. pachyacanthus was the larva of $L$. teres. The subsequent records of cysticercoids of $L$. teres were from Russia: in Gammarus locusta (L.) from the coastal area of the Barents Sea (Ouspenskaia 1960), in G. lacustris Sars from the Karasuk Lakes, West Siberia (Tolkacheva 1971) and from the same host from several lakes in South Ural (Shapkin and Gulyaev 1973). However, Gulyaev and Ust'yantsev (1987) recognised that the latter record belonged to another species described by them, Lateriporus spasskii. An additional record of L. teres was from G. lacustris from Kazakhstan (Kul'kina 1990).

The number and the length of rostellar hooks of our specimens fit the descriptions of L. teres (see Matevosyan 1963, Tolkacheva 1971). The ratio of the length of the blade to the total hook length in our specimens (0.39) has an intermediate value between $L$. teres $(0.35)$ and $L$. spasskii $(0.41-0.42$, data for both species from Gulyaev and Ust'yantsev 1987), which questions the reliability of this distinguishing character.

The cysticercoids found by us had no cercomers. This is in agreement with the experimental observations of Gulyaev (1998) on the life cycle of Lateriporus clerci (Johnston, 1912) revealing early detachment of the tail-like cercomer during the larval development.

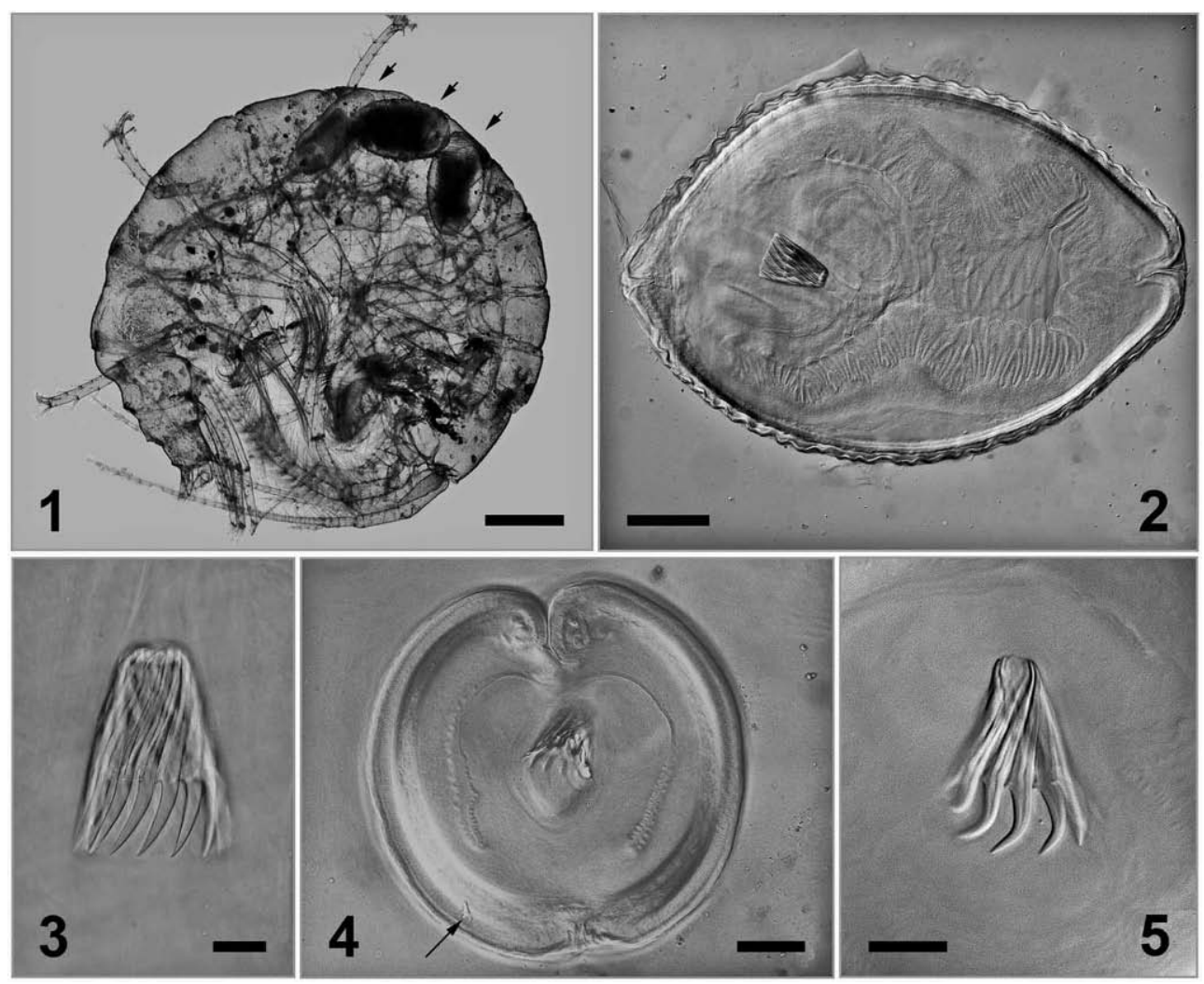

Figs 1-5. Cysticercoids of Lateriporus teres and Microsomacanthus microsoma from Echinogammarus tibaldii: 1. E. tibaldii infected with three cysticercoids (arrowed) of L. teres. 2. Cysticercoid of L. teres, general view. 3. Cysticercoid of $L$. teres, crown of rostellar hooks. 4. Cysticercoid of M. microsoma, general view (arrow indicates an embryonic hook). 5. Cysticercoid of M. microsoma, crown of rostellar hooks. Scale bars $=1 \mathrm{~mm}(1), 200 \mu \mathrm{m}(2), 40 \mu \mathrm{m}(3,4), 20 \mu \mathrm{m}(5)$ 
Spasskii (1954) introduced the term "strobylocysta" for the cysticercoid of Lateriporus; two synonymous terms, "strobilocysticercoid" and "strobilocercoid", were proposed by subsequent authors (see Chervy 2002). In the attempt to unify the larval cestode terminology (Chervy 2002), "strobilocercoid" is included as a synonym of "monocysticercoid". However, the morphology of the cysticercoids of Lateriporus corresponds rather to that of cercocysticercoids than to monocysticercoids. This discrepancy indicates the further need for improvement of the terminology for metacestodes.

Lateriporus teres occurs in waterfowl and gulls in the Holarctic Region (Matevosyan 1963, Schmidt 1986). Until now, it has not been recorded in Italy (see Bona et al. 1995). The present study is also a new host record for E. tibaldii.

Microsomacanthus microsoma (Creplin, 1829) (Figs 4, 5 and 7)

Five cysticercoids of $M$. microsoma were found in a single host specimen (prevalence $0.12 \%$, intensity 5 , mean abundance 0.006$)$. They were located in the 3 rd (2 larvae) and 4th thoracic segments, and in the 2nd and 3rd abdominal segments.

The cysticercoids (Figs 4, 5, 7) had oval to spherical cysts, $185-225 \times 180-220(206 \times 190, \mathrm{n}=5)$. The cyst wall consisted of four distinct layers. The external layer was transparent, homogenous, with a maximum thickness of 4-5 $(n=4)$. The second layer was transversely striated, with a thickness of 5-11 $(9, \mathrm{n}=6)$. The third layer was translucent, with a thickness of 4-7 $(5, n=6)$. The internal layer consisted of fibrous and granular elements, with a thickness of 5-11 $(8, n=5)$. The calcareous corpuscles were concentrated near the anterior part

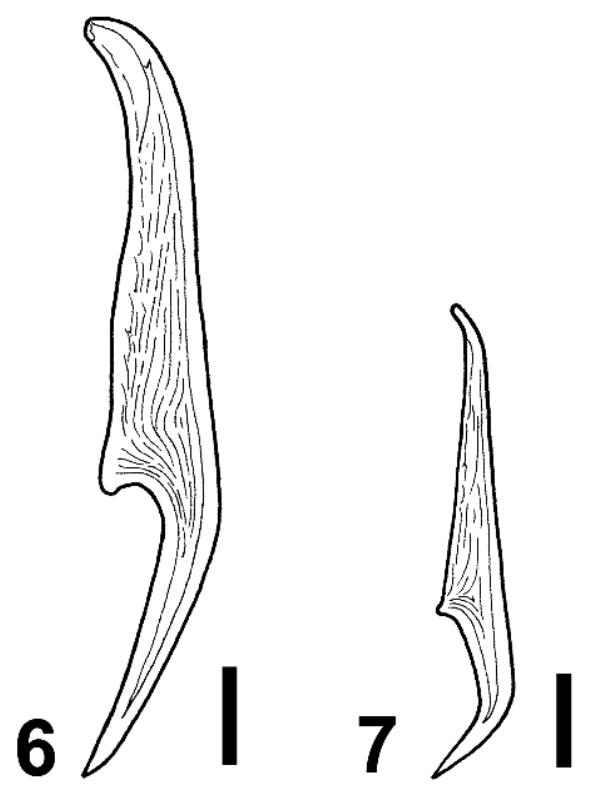

Figs 6 and 7. Rostellar hooks of cysticercoids from Echinogammarus tibaldii: 6. Rostellar hook of L. teres. 7. Rostellar hook of M. microsoma. Scale bars $=20 \mu \mathrm{m}(6), 10 \mu \mathrm{m}$ (7) of the larva. The scolex was rounded, 88-110 × 105-130 (99 $\times 119, \mathrm{n}=5)$. The suckers were elliptical, muscular, $45-68 \times$ 33-63 $(55 \times 50, \mathrm{n}=9)$. The rostellar sac was 83-100 $(91, \mathrm{n}=$ 5) long and 55-65 $(60, n=5)$ wide, with a wall thickness of $3(\mathrm{n}=5)$, passing beyond the posterior margins of the suckers. The retracted rostellum was $68-78(72, \mathrm{n}=5)$ long and $35-53(43, \mathrm{n}=5)$ wide; the wall was $2(\mathrm{n}=5)$ thick. The rostellar hooks were $10(\mathrm{n}=5)$ in number, arranged with their guards pointing outwards. The hook total length was 48-50 $(n=2)$, with the blade $18(n=2)$ long and the hook base $30-33$ $(\mathrm{n}=2)$ long. The blade length/total length ratio was $0.63-0.66$. The cercomer was very long and 48-68 $(56, \mathrm{n}=3)$ wide. Embryonic hooks were often distinct in the cercomer and in the cyst wall; they differed in shape and length: the thinner hooks were $15(\mathrm{n}=1)$ long and the massive hooks were 13 $(\mathrm{n}=3)$ long.

Lühe (1910) reported cysticercoids similar to those found in our study as "Cysticercus limnaei (Villot)" from the freshwater snail Radix peregra (Müller) and from the copepods Eucyclops serrulatus (Fischer), the latter identified as a larva of M. microsoma. Spasskaya (1966) summarised earlier records of cysticercoids of $M$. microsoma and reported amphipods and copepods as intermediate hosts and freshwater snails as paratenic hosts. The following amphipods have been recorded as intermediate hosts: Gammarus locusta (L.) from the White Sea (Zelikman 1955, cited in Spasskaya 1966), G. locusta and Ampithoe rubricata (Montagu) from the Barents Sea (Ouspenskaia 1960), G. lacustris from Kazakhstan (Kul'kina 1990) and Pallasea quadrispinosa Sars (= Pallasiola quadrispinosa) in Karelia (Shteyn 1958, cited after Spasskaya 1966). The present study is the first record in amphipods of the genus Echinogammarus Stebbing.

The present cercocysticercoids are identified on the basis of their rostellar hooks, which are 48-50 $\mu \mathrm{m}$ long (blade 18 $\mu \mathrm{m}$ long). Similar measurements for the rostellar hooks of M. microsoma were reported by Fuhrmann (1913) and Spasskaya (1966). Among the European species, the most similar congeners are $M$. compressa (Linton, 1892) (hook 55-57 $\mu \mathrm{m}$, blade $24 \mu \mathrm{m}$ ), M. paracompressa (Czaplinski, 1956) (hook 56 $\mu \mathrm{m}$, blade $20 \mu \mathrm{m})$, M. microskrjabini Spasskii et Yurpalova, 1964 (hook 53-56 $\mu \mathrm{m}$, blade 20-22 $\mu \mathrm{m}$ ), M. heterospinus Spasskii et Yurpalova, 1964 (hook 45-47 $\mu \mathrm{m}$, blade 14-17 $\mu \mathrm{m}$ ) and M. recurvata Spasskaya et Spasskii, 1961 (hook 45-47 $\mu \mathrm{m}$, blade 16-17 $\mu \mathrm{m})$. For morphological data of European Microsomacanthus spp., see Spasskaya (1966).

Adult cestodes of M. microsoma are parasites of waterfowl and gulls in the Holarctic region (Spasskaya 1966, Schmidt 1986).

There are very few published records on amphipod intermediate hosts of cestode parasites of aquatic vertebrates in Italy. E. tibaldii from the River Tirino (Central Italy) was reported to be the intermediate host of the fish cestode Cyathocephalus truncatus Pallas, 1781 (see Orecchia et al. 1978). Later, in E. stammeri Karaman from the River Brenta (Northern Italy), larvae of C. truncatus were encountered (Dezfuli and Scholz 1995). The present study is the first 
record of larvae of cyclophyllidean cestodes in Echinogammarus tibaldii.

Acknowledgments. We are grateful to Professor Z.P. Świderski (Institute of Parasitology, Warsaw) for his assistance and stimulating interest. Thanks are due to F. Bisonni (Fisheries Cooperation, Lake Piediluco) for his assistance in collecting amphipods and to A. Lui (University of Ferrara) for her technical assistance. This investigation was supported in part by grants from the Italian Ministry of the University and Scientific Research and Technology. The morphological study was carried out using the technical facilities obtained within the BioCORE project (leader Dr V. Peneva, Central Laboratory of General Ecology, Sofia) funded by the Ministry of Education and Science of the Republic of Bulgaria.

\section{References}

Beveridge I. 2001. The use of life-cycle characters in studies of the evolution of cestodes. In: (Eds. D.T.J. Littlewood and R.A. Bray) Interrelationships of the Platyhelminthes. Taylor and Francis, London, 250-256.

Bona F., Buriola E., Cerioni S., di Cave D., Orecchia P., Paggi L. 1995. Cestoda, Monogenea. In: (Eds. A. Minelli, S. Ruffo and S. La Posta) Checklist delle specie della fauna Italiana. Calderini, Bologna, $28 \mathrm{pp}$.

Chervy L. 2002. The terminology of larval cestodes or metacestodes. Systematic Parasitology, 52, 1-33. DOI: 10.1023/A:101508 6301717.

Dezfuli B.S., Scholz T. 1995. Cyathocephalus truncatus (Cestoda: Spathebothridae) in its intermediate host Echinogammarus stammeri (Amphipoda) from the River Brenta, Northern Italy. Parassitologia, 37, 59-62.

Fuhrmann O. 1913. Nordische Vogelcestoden aus dem Museum von Göteborg. Göteborgs Kungliga Vetenskaps-och Vitterhetssamhälles Handlingar. Fjärde Följden, 15, 1-41.

Georgiev B.B. 2003. Cestoda (Tapeworms). In: (Eds. M. Hutchins, D.A. Thoney and N. Schlager) Grzimek's Animal Life Encyclopedia. Lower Metazoans and Lesser Deuterostomes. 2nd edition. Vol. 1. Gale Group, Farmington Hills, Michigan, 225243.

Georgiev B.B., Bray R.A, Littlewood D.T.J. 2006. Cestodes of small mammals: taxonomy and life cycles. In: (Eds. S. Morand, B.
Krasnov and R. Poulin) Micromammals and macroparasites: from evolutionary ecology to management. Springer Verlag, Tokyo, 29-62. DOI: 10.1007/978-4-431-36025-4 3.

Gulyaev V.D. 1998. Development of the metacestode Lateriporus clerci (Cestoda, Cyclophyllidea, Dilepididae). Zoologicheskiy Zhurnal, 77, 1103-1110 (In Russian).

Gulyaev V.D., Ust'yantsev V.V. 1987. New species of cestodes Lateriporus spasskii sp. n. (Dilepididae). In: (Ed. A.I. Cherepanov) Novye i maloizvestnye vidy fauny Sibiri. Nasekomye, kleshchi i gel'minty. Nauka, Novosibirsk, 74-80 (In Russian).

Joyeux C., Baer J.-G. 1936. Faune de France. 30. Cestodes. Paul Lechevalier, Paris, 613 pp.

Kul'kina L.V. 1990. Helminth larvae of Gammarus lacustris in waters of the Markakol'sk valley. In: (Ed. E.G. Sidorov) Ekologiya i Morfologiya Gel'mintov Zhivotnykh Kazakhstana. Nauka Kazakhskoy SSR, Alma-Ata, 116-124 (In Russian, cited after CABI Abstracts).

Lühe M. 1910. Parasitische Plattwürmer. 2. Cestodes. In: (Ed. A. Brauer) Die Süsswasserfauna Deutschlands. Gustav Fischer Verlag, Jena, $153 \mathrm{pp}$.

Matevosyan E.M. 1963. Foundations of Cestodology. Vol. 3. Dilepidoidea - cestodes of domestic and wild animals. Izd. Akademii Nauk SSSR, Moscow, 687 pp. (In Russian).

Orecchia P., Paggi P., Manilla G., Rossi G. 1978. Parassitofauna di Salmo trutta L. del fiume Tirino. Nota IV - Ricerca degli ospiti intermedi di Cyathocephalus truncatus (Pallas, 1781) e Dentitruncus truttae Sinzar, 1955. Parassitologia, 20, 176181.

Ouspenskaia A.V. 1960. Parasitofaune des crustacés benthiques de la Mer de Barents. Annales de Parasitologie Humaine et Comparée, 35, 221-242.

Schmidt G.D. 1986. CRC Handbook of Tapeworm Identification. CRC Press, Boca Raton, Florida, 675 pp.

Shapkin V.A., Gulyaev V.D. 1973. On the biology of cestodes of the genus Lateriporus Fuhrmann. Parazitologiya, 7, 509-512 (In Russian).

Spasskaya L.P. 1966. Cestodes of birds of the USSR. Hymenolepididae. Nauka, Moscow, 698 pp. (In Russian).

Spasskii A.A. 1954. On the life cycle of the dilepidids of the genus Lateriporus (Cestoda: Dilepididae). Trudy GELAN, 7, 176179 (In Russian).

Tolkacheva L.M. 1971. Study of the role of the copepods and amphipods as intermediate hosts of cestodes from birds. Trudy GELAN, 21, 99-110 (In Russian). 